\title{
Errata: Sinusoidal rotating grating for speckle reduction in laser projectors: feasibility study
}

Sigbjørn Vindenes Egge

Norwegian University of Science and Technology

Department of Electronics and Telecommunications

7491 Trondheim, Norway

E-mail: sve@iet.ntnu.no

M. Nadeem Akram

Vestfold University College

Institute for Microsystems Technology

P.O. Box 2243

3103 Tønsberg, Norway

Vladimir Kartashov

poLight AS

P.O. Box 163

3192 Horten, Norway

Kristine Welde

Norwegian University of Science and Technology

Department of Electronics and Telecommunications

7491 Trondheim, Norway

\section{Zhaomin Tong}

Vestfold University College

Institute for Microsystems Technology

P.O. Box 2243

3103 Tønsberg, Norway

\section{Ulf Österberg}

Astrid Aksnes

Norwegian University of Science and Technology

Department of Electronics and Telecommunications

7491 Trondheim, Norway

[DOI: $10.1117 / 1.3640737]$

This article [Opt. Eng. 50, 083202 (2011)] was originally published on 4 August 2011 with errors in the equation appearing on page 3 , paragraph 2 , line 7 . The correct equation is:

$s_{i}^{(n)}(N)=\left(2 R_{1} i / d\right) \sin (\pi n /(2 N))$.

The corrected manuscript was published online 31 August 2011 and it appears correctly in print. 